\title{
Experimental substantiation of hyperthermic exogenous and endogenous factors prompt neutralization in burn injuries
}

\author{
Roman Chornopyshchuk \\ Department of General Surgery, National Pirogov Memorial Medical University, Vinnytsya, Ukraine \\ Author's ORCID iD, academic degrees and contribution are available at the end of the article \\ Corresponding author: r.chornopyshchuk@gmail.com \\ Manuscript received March 23, 2021; revised manuscript April 16, 2021; published online April 28, 2021
}

\begin{abstract}
Background: High mortality and disability of patients with critical and supercritical burns, long-term treatment, unsatisfactory aesthetic and functional results lead to the search for ways to provide assistance aimed at counteracting the formation of a mass of necrotic tissue, which is crucial for life or death of the victim.

Material and methods: The experimental study was performed on 60 sexually mature Wistar rats, which were on a regular diet and weighed $150-160$ g. The experimental animals were divided into the main and control groups and were used to simulate burns with boiling water of IIb degree.

Results: The traumatic effect of hyperthermic exogenous and endogenous damage factors of the animals in the main group were immediately neutralized by a gauze napkin soaked in water at a temperature of $18-20{ }^{\circ} \mathrm{C}$ immediately after the simulation of burns, the duration of which became the criterion for dividing them into subgroups. In animals of subgroup 1 the time of application of a wet wipe to the burn area was 1 min., in the $2^{\text {nd }}$ subgroup it was 5 min., $3^{\text {rd }}$ subgroup $-10 \mathrm{~min}$., $4^{\text {th }}$ subgroup $-15 \mathrm{~min}$., $5^{\text {th }}$ subgroup $-20 \mathrm{~min}$. The application napkin was changed when it was heated to $34^{\circ} \mathrm{C}$. Such applications were not performed to the animals of the control group.

Conclusions: The conclusion was made on the necessity of prompt neutralization of traumatic action of hyperthermic exogenous and endogenous damage factors as the main elements of burn wound depth. For a broader understanding of action mechanisms of the suggested technology of self-help and mutual first aid as well as the nature of the impact of neutralization directly on the tissues, it is advisable to supplement the research with morphological methods. Key words: hyperthermic factors, burns, neutralization, first aid, necrotic tissues.
\end{abstract}

Cite this article

Chornopyshchuk R. Experimental substantiation of hyperthermic exogenous and endogenous factors prompt neutralization in burn injuries. Mold Med J. 2021;64(2):53-57. https://doi.org/10.52418/moldovan-med-j.64-2.21.10.

\section{Introduction}

Burns are one of the most fearsome and widespread forms of injury, which is characterized by prolonged, expensive treatment with not always positive outcomes and a high risk of various complications at different stages of the wound process [1].

The government and health care system of Ukraine today cannot afford the significant financial costs for treating patients with burns as opposed to countries with higher welfare levels. For comparison, in Germany, a total of $€ 270000$ are spent per patient with burns per year, in the UK it is around $€ 63157$, given significant costs of treating patients in intensive care, long and expensive rehabilitation and a high risk of disability [2].

Therefore, the pathogenetic substantiation of knowledge on the provision of self-help, mutual assistance and first aid at the site of injury at the prehospital and hospital-based levels by prompt neutralization of exogenous and endogenous factors of injury with ordinary water at room temperature is so relevant [3].

Objective: experimental study of effective prompt neu- tralization of the traumatic effects of exogenous and endogenous factors of burn injuries.

\section{Material and methods}

The experimental study was performed on 60 sexually mature Wistar rats, which were on a normal diet, weighing 150-160 g. The study followed the international rules and principles of "The European Convention for the Protection of Vertebrate Animals used for Experimental and other Scientific Purposes" (Strasbourg, 18.03.1986), directives of the Council of the European Economic Association for the protection of vertebrate animals (Strasbourg, 24.11.1986), Directive 2010/63/EU of European Parliament and Council on the protections of animals used for scientific purposes, "General ethical guidelines for experiments on animals" (Kyiv, 2011).

Experimental animals were divided into the main and control groups. Simulation of IIb degree burn injuries with boiling water with an area of $27 \mathrm{~cm}^{2}$ was performed on the rats of both groups according to the method suggested by Pfurtscheller et al. [4]. Prompt neutralization of the trau- 
matic action of hyperthermic exogenous and endogenous damage factors of animals in the main group was carried out with a gauze napkin soaked in water at a temperature of 18-20 ${ }^{\circ} \mathrm{C}$ immediately after the simulation of burns. The duration of traumatic action became a criterion for division of animals into subgroups. In animals of subgroup 1 the time of application of a wet wipe to the burn area was $1 \mathrm{~min}$, in the 2 nd subgroup it was $5 \mathrm{~min}$, 3rd subgroup - $10 \mathrm{~min}$., 4 th subgroup - $15 \mathrm{~min}$, 5th subgroup - $20 \mathrm{~min}$. The application napkin was changed when it was heated to $34^{\circ} \mathrm{C}$. Such applications were not performed to the animals of the control group.

The studies were performed on the $1^{\text {st }}, 3^{\text {rd }}, 5^{\text {th }}, 7^{\text {th }}, 14^{\text {th }}$ day and included assessment of the appearance of animals and wounds, determination of temperature in the center of the injured area with infrared non-contact thermometer ThermoFlash LX-26 (SN: 103300706647) compared with that in a homogeneous intact area, analysis of the wound defect area by a planimetric method using mobile application "LesionMeter" $[5,6]$. On days 5, 14 blood was taken from the tail vein with leukocyte count [7].

Statistical processing of the obtained results was performed using Microsoft Excel 2016 software and "STATISTICA 5.5" (owned by of National Pirogov Memorial Medical University, Vinnytsya, Ukraine, license No AXXR910A374605FA) with determination of the arithmetic mean and its error $(M \pm m)$, Student's criterion $(t)$ and reliability index (p). Differences at $\mathrm{p} \leq 0.05$ (95.5\%) were considered reliable [8].

\section{Results and discussion}

On the first day the formation of gray burn necrosis in the injured area with islets of shading was determined in animals of all groups. Size of the islets increased in proportion to the decrease in neutralization time, mostly in the control group (fig. 1).

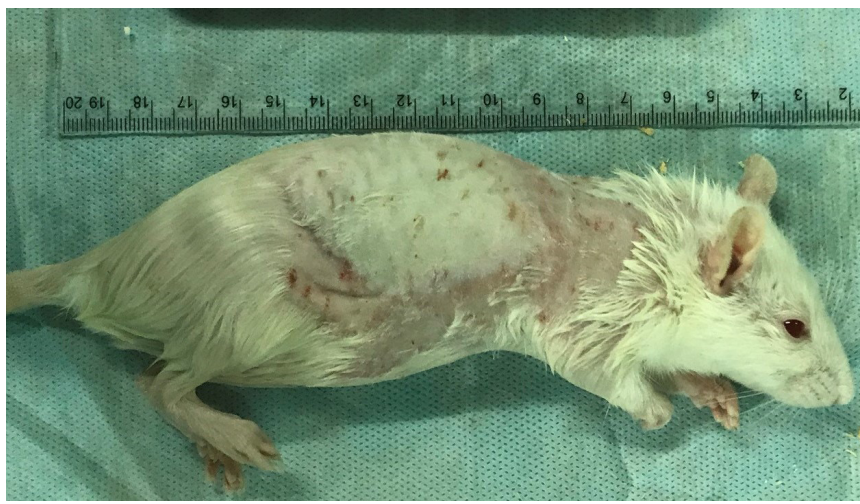

Fig. 1. Wound appearance of the animal in the control group on the $1^{\text {st }}$ day of experimental modeling, the formation of burn necrosis

From day 3 the necrotic eschar of the studied animals, which was particularly dense in the rats of the control group, was firmly fixed to the adjacent tissues. In addition, forced position of the body in the animals of the control group and main group 1 with curved torso towards the injury, bowed head and cautious behavior when moving, which suggests significant pain at the site of injury, was determined.

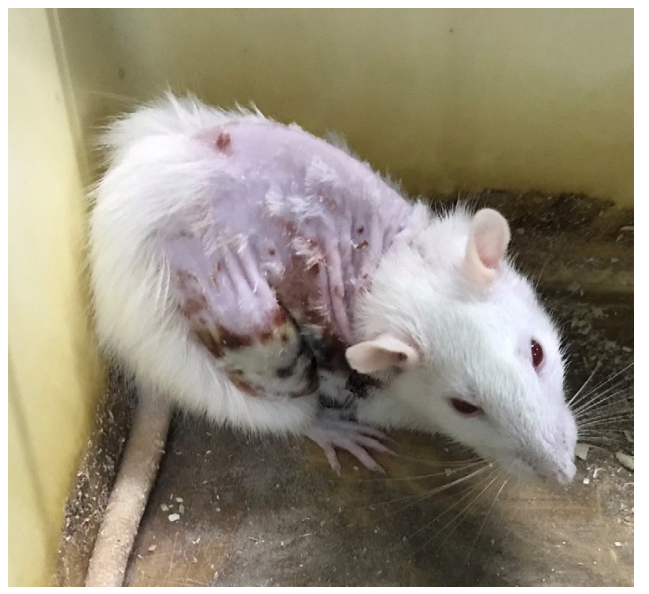

Fig. 2. The characteristic position of the experimental animal of the control group on the $3^{\text {rd }}$ day of observation
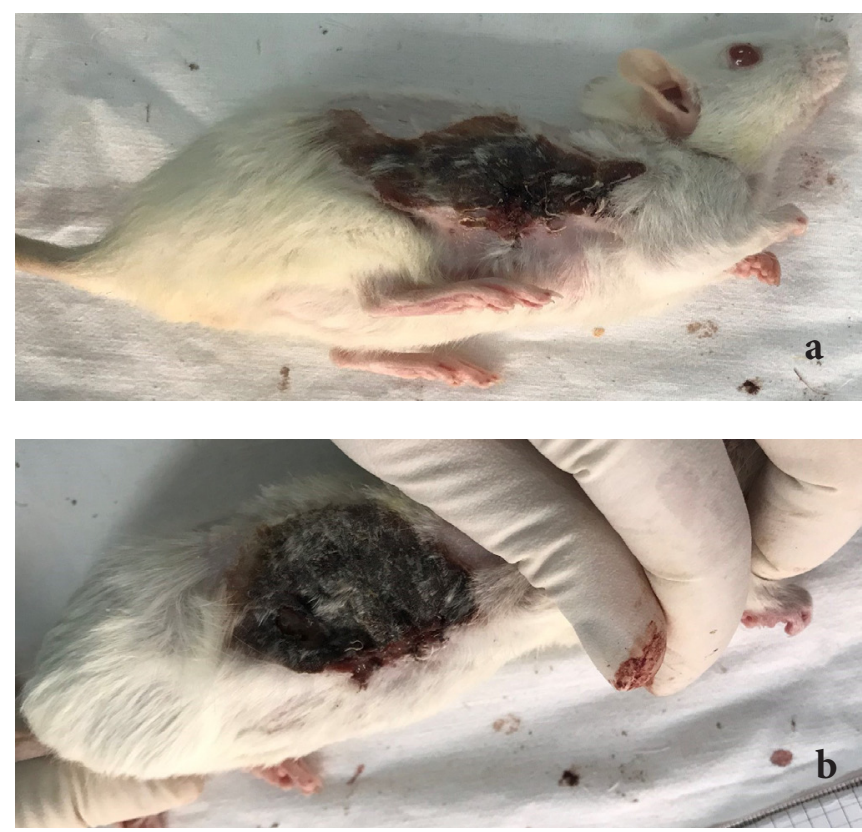

Fig. 3. Wound appearance of animals in the main-5 (a) and control (b) groups on the $7^{\text {th }}$ day of experimental modeling, the wound is covered by necrotic eschar

On day 14 partial exfoliation of the necrotic eschar with signs of epithelialization of the wound surface was observed in animals of the main group, the manifestations of which were especially noticeable in groups $3,4,5$. The wound defect of animals of the control group remained covered with necrotic eschar (fig. 4).

Complete healing of the wound defect in animals of the main group was determined on days 19-20, while in the control group minor residual wounds with signs of epithelialization were noticed. 

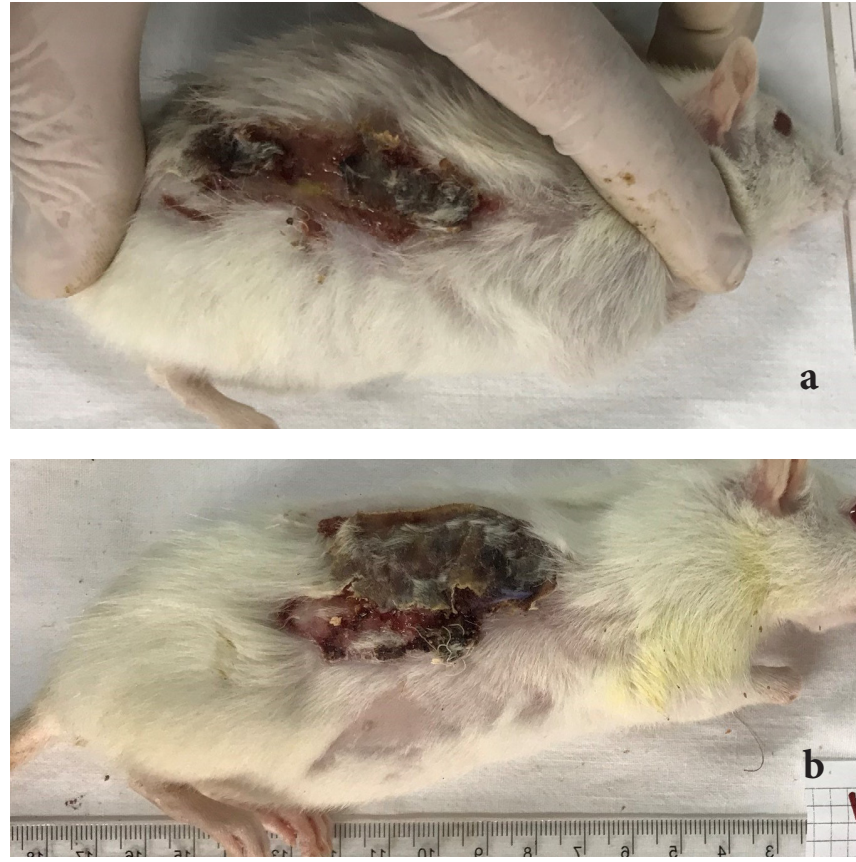

Fig. 4. Wound appearance of animals in the main-5 (a) and control (b) groups on the $14^{\text {th }}$ day of experimental modeling, signs of necrotic eschar exfoliation and marginal epithelialization of wounds of animals in the main group

The skin surface temperature of the rats before the experiment was $37.3 \pm 0.4{ }^{\circ} \mathrm{C}$. After application of the heated liquid to the skin surface, a sharp increase in temperature in this area to $52.8 \pm 1.7^{\circ} \mathrm{C}$ was determined. The change of wet wipes for neutralization in the animals of the main group was performed after the temperature in the burn area increased over $38.5^{\circ} \mathrm{C}$. After completion of neutralization in the appropriate time for the animals of main groups 1,2 , 3,4 , the temperature of the injured area differed from that on a symmetrical intact surface with an average difference of $1.8 \pm 0.3{ }^{\circ} \mathrm{C}$ for 30 minutes. Along with this, in the main groups 1, 2, 3, 4 there was a repeated increase in the temperature of the injured area compared to the intact one. And only in the main group 5 after 20 minutes of application of a wet wipe, the heating of the latter was not determined, and the temperature of the injured area corresponded to that on a healthy body surface. 1 hour after burn modeling, the dif- ference in temperatures of the compared areas in animals of all groups was not reliably detected, which persisted throughout the subsequent observation period. The results of determining the area of the wound defect are shown in table 1 .

Thus, on the $1^{\text {st }}$ day after modeling the area of wound defect in animals of the main group 1 was $25.89 \pm 0.39 \mathrm{~cm}^{2}$, group $2-24.85 \pm 0.26 \mathrm{~cm}^{2}$, group $3-24.50 \pm 0.33 \mathrm{~cm}^{2}$, group $4-23.93 \pm 0.25 \mathrm{~cm}^{2}$, group $5-22.46 \pm 0.27 \mathrm{~cm}^{2}$; this index was higher in the control group and amounted to $26.14 \pm 0.32 \mathrm{~cm}^{2}$. This difference between the main groups 4, 5 and the control group was reliable. At a later date, these patterns were similar maintaining a positive tendency to reduce the size of the wound defect in animals the temperature factor of which was neutralized. On day 14 these indices constituted $14.94 \pm 0.31 \mathrm{~cm}^{2}, 13.37 \pm 0.28 \mathrm{~cm}^{2}, 13.06 \pm$ $0.35 \mathrm{~cm}^{2}, 13.04 \pm 0.21 \mathrm{~cm}^{2}, 12.66 \pm 0.19 \mathrm{~cm}^{2}, 16.08 \pm 0.27$ $\mathrm{cm}^{2}$ in animals of the main and control groups, respectively.

The leukocyte count analysis revealed general patterns for animals of all studied groups: increase in the relative number of eosinophils, monocytes, rod-shaped neutrophils with a decrease in the population of segmental leukocytes and lymphocytes (tab. 2). Difference between the level of rod-shaped neutrophils on days 5 and 14 in the control $(15.3 \pm 1.1 \% ; 9.5 \pm 0.7 \% ;)$ and main groups $(6.8 \pm 0.7 \%, 6.0$ $\pm 0.7 \% ; 5.3 \pm 0.5 \%, 3.9 \pm 0.7 \% ; 4.5 \pm 0.9 \%, 5.4 \pm 0.8 \%$; $6.0 \pm 0.8 \%, 4.8 \pm 0.6 \% ; 4.9 \pm 0.7 \%, 5.2 \pm 0.4 \%$ in $1,2,3,4$, 5 , respectively) was statistically significant, which indicates a more pronounced systemic inflammatory reaction in animals without neutralization of traumatic agent. Statistical differences in indices of a relative level of lymphocytes on the $5^{\text {th }}$ day in animals of the control group $(64.2 \pm 2.2 \%)$ to $71.2 \pm 1.7 \%, 73.0 \pm 1.5 \%, 73.4 \pm 2.1 \%, 70.9 \pm 0.9 \%, 70.8 \pm$ $1.1 \%$ in the main groups $1,2,3,4,5$, respectively, confirms the intensity of immunity of the latter.

Thus, the need for prehospital care for patients with burns is not in doubt [9]. It seemed as though the problem was solved and clear step-by-step guidelines for burn care of various genesis and severity were developed [10]. A number of experiments on animals and observations on humans were carried out where the mechanisms of their action were carefully studied and pathogenetically substantiated [11].

Table 1. Dynamics of change in the size of burn injury in the studied rats $\left(\mathrm{cm}^{2}\right)$

\begin{tabular}{|c|c|c|c|c|c|}
\hline \multirow{2}{*}{ Observation group } & \multicolumn{5}{|c|}{ Terms of observation } \\
\cline { 2 - 6 } & Day 1 & Day 3 & Day 5 & Day 7 & Day 14 \\
\hline Main group-1 & $25.89 \pm 0.39$ & $25.92 \pm 0,33$ & $23.68 \pm 0.35^{*}$ & $19.01 \pm 0.29$ & $14.94 \pm 0.31^{*}$ \\
\hline Main group-2 & $24.85 \pm 0.26^{*}$ & $25.17 \pm 0.51^{*}$ & $22.21 \pm 0.39^{*}$ & $18.37 \pm 0.40^{*}$ & $13.37 \pm 0.28^{*}$ \\
\hline Main group-3 & $24.50 \pm 0.33^{*}$ & $24.09 \pm 0.46^{*}$ & $21.78 \pm 0.37^{*}$ & $18.51 \pm 0.38^{*}$ & $13.06 \pm 0.35^{*}$ \\
\hline Main group-4 & $23.93 \pm 0.25^{*}$ & $23.32 \pm 0.39^{*}$ & $21.53 \pm 0.45^{*}$ & $18.35 \pm 0.25^{*}$ & $13.04 \pm 0.21^{*}$ \\
\hline Main group-5 & $22.46 \pm 0.27^{*}$ & $21.90 \pm 0.45^{*}$ & $20.01 \pm 0.33^{*}$ & $17.52 \pm 0.31^{*}$ & $12.66 \pm 0.19^{*}$ \\
\hline Control group & $26.14 \pm 0.32$ & $26.75 \pm 0.41$ & $25.31 \pm 0.39$ & $19.66 \pm 0.22$ & $16.08 \pm 0.27$ \\
\hline
\end{tabular}

Note: ${ }^{*} \mathrm{p} \leq 0.05$ - index of statistical reliability in comparison with the control group. 
Table 2. Dynamics of leukocyte count in rats with burns

\begin{tabular}{|c|c|c|c|c|}
\hline \multirow{2}{*}{ Hematological parameters } & \multirow{2}{*}{ Observation group } & \multicolumn{3}{|c|}{ Terms of observation } \\
\hline & & Intact & Day 5 & Day 14 \\
\hline \multirow{6}{*}{ Eosinophils, \% } & Main group-1 & \multirow{6}{*}{$1.8 \pm 0.5$} & $4.0 \pm 0.5$ & $3.3 \pm 0.4$ \\
\hline & Main group-2 & & $4.2 \pm 0.3$ & $3.7 \pm 0.5$ \\
\hline & Main group-3 & & $3.7 \pm 0.5$ & $3.5 \pm 0.2$ \\
\hline & Main group-4 & & $3.9 \pm 0.6$ & $3.2 \pm 0.4$ \\
\hline & Main group-5 & & $3.5 \pm 0.4$ & $3.6 \pm 0.3$ \\
\hline & Control group & & $4.5 \pm 0.7$ & $3.9 \pm 0.5$ \\
\hline \multirow{6}{*}{ Rod-shaped neutrophils, \% } & Main group-1 & \multirow{6}{*}{$2.9 \pm 0.7$} & $6.8 \pm 0.7^{*}$ & $6.0 \pm 0.7^{*}$ \\
\hline & Main group-2 & & $5.3 \pm 0.5^{*}$ & $3.9 \pm 0.7^{*}$ \\
\hline & Main group-3 & & $4.5 \pm 0.9^{*}$ & $5.4 \pm 0.8^{*}$ \\
\hline & Main group-4 & & $6.0 \pm 0.8^{*}$ & $4.8 \pm 0.6^{*}$ \\
\hline & Main group-5 & & $4.9 \pm 0.7^{*}$ & $5.2 \pm 0.4^{*}$ \\
\hline & Control group & & $15.3 \pm 1.1$ & $9.5 \pm 0.7$ \\
\hline \multirow{6}{*}{ Segmented neutrophil, \% } & Main group-1 & \multirow{6}{*}{$16.8 \pm 2.1$} & $9.3 \pm 0.8$ & $12.7 \pm 0.6$ \\
\hline & Main group-2 & & $8.4 \pm 0.5$ & $13.3 \pm 0.8$ \\
\hline & Main group-3 & & $9.5 \pm 0.6$ & $12.9 \pm 0.7$ \\
\hline & Main group-4 & & $10.1 \pm 1.0$ & $14.4 \pm 0.9^{*}$ \\
\hline & Main group-5 & & $11.5 \pm 0.8^{*}$ & $13.8 \pm 0.7^{*}$ \\
\hline & Control group & & $8.1 \pm 0.9$ & $11.6 \pm 0.6$ \\
\hline \multirow{6}{*}{ Lymphocytes, \% } & Main group-1 & \multirow{6}{*}{$72.8 \pm 3.5$} & $71.2 \pm 1.7^{*}$ & $71.0 \pm 1.3$ \\
\hline & Main group-2 & & $73.0 \pm 1.5^{*}$ & $70.3 \pm 1.9$ \\
\hline & Main group-3 & & $73.4 \pm 2.1^{*}$ & $69.0 \pm 1.6$ \\
\hline & Main group-4 & & $70.9 \pm 0.9^{*}$ & $70.1 \pm 1.6$ \\
\hline & Main group-5 & & $70.8 \pm 1.1^{*}$ & $69.2 \pm 1.8$ \\
\hline & Control group & & $64.2 \pm 2.2$ & $68.6 \pm 2.5$ \\
\hline \multirow{6}{*}{ Monocytes, \% } & Main group-1 & \multirow{6}{*}{$3.7 \pm 0.9$} & $8.7 \pm 0.6$ & $6.8 \pm 0.4$ \\
\hline & Main group-2 & & $9.1 \pm 0.8$ & $7.3 \pm 0.5$ \\
\hline & Main group-3 & & $8.9 \pm 0.7$ & $7.9 \pm 0.6$ \\
\hline & Main group-4 & & $9.1 \pm 0.6$ & $8.5 \pm 0.3$ \\
\hline & Main group-5 & & $9.3 \pm 0.7$ & $8.2 \pm 0.4$ \\
\hline & Control group & & $7.9 \pm 0.9$ & $6.1 \pm 0.6$ \\
\hline
\end{tabular}

Note: ${ }^{*} \mathrm{p} \leq 0.05-$ index of statistical reliability in comparison with the control group.

However, numerous fundamental differences in the results of these studies indicate the opposite. One of the main differences is the terminological discrepancy, which in essence leads to a misunderstanding of one of the most important elements of first aid - "cooling". Existing studies have clearly established the negative effects of low temperatures (ice and water at $<10^{\circ} \mathrm{C}$ ) on local tissues, causing vasoconstriction with additional tissue damage in the burn area, disproving previous theories of rapid aggressive wound cooling [12]. Moreover, it has been proven that even topical use of low temperature agents can cause a number of systemic disorders in the body characteristic of general hypothermia [13]. Therefore, the most effective and safe water temperature to date is set in the range of $15-22^{\circ} \mathrm{C}$, and in some cases even $37^{\circ} \mathrm{C}$ in order to improve microcirculatory perfusion [14]. In view of this, in our opinion, in contrast to the term "cool- ing" it would be appropriate to use the term "neutralization", which more clearly reflects the mechanisms and principles of this process.

Another controversial element is the time of onset and duration of local neutralizing action on the injured area. If the opinion of researchers mostly coincides with the need for the earliest possible neutralization of the traumatic agent, the terms suggested by various scientists are fundamentally different [15]. Such discrepancies led to a similar study, which clearly confirmed positive effect of prompt neutralization of traumatic effects of exogenous and endogenous factors of thermal damage on the wound process, wound healing and reducing the activity of general inflammatory reaction on the example of experimental burns on animals. Moreover, the results of research clearly confirmed the interrelation between the duration of care provided and the 
nature of further course of the pathological process. Thus, it was established that 20 minutes can be considered the optimal effective duration of prompt neutralization under the conditions of experimental modeling of burns with boiling water in rats. However, it is necessary to keep in mind the numerous anatomical and physiological features of the course of processes in these animals, which are substantially different from human ones. With this in mind, the results obtained should by no means be extrapolated to the human body, which requires further clinical study.

\section{Conclusions}

Results of the obtained experimental studies allowed to objectively confirm the importance and necessity of prompt neutralization of the traumatic effect of hyperthermic exogenous and endogenous damage factors as the main elements of burn wound depth formation. This was confirmed not only by the data of visual analysis of the wound area and the dynamics of changes in planimetric parameters, which indicated a positive effect of neutralizing the traumatic agent, but also the results of hematological analysis. Thus, with the exception of monocytes, normal indices of eosinophils, rodshaped and segmental neutrophils and lymphocytes were better restored in the blood of animals of the main groups, which indicated a rapid attenuation of the inflammatory process and a reduction in burn depth.

For a broader understanding of action mechanisms of the suggested technology of self-help, mutual assistance and first aid and the nature of neutralization impact directly on the tissues it will be appropriate to supplement the research with morphological methods.

\section{References}

1. Buja Z, Arifi H, Hoxha E, Duqi S. Surgical treatment of burns sequelae. Our experience in the Department of Plastic and Reconstructive Surgery, Pristina, Kosovo. Ann Burns Fire Disasters. 2015 Sep 30;28(3):205-209.

2. Mirastschijski U, Sander JT, Weyand B, Rennekampff HO. Rehabilitation of burn patients: an underestimated socio-economic burden. Burns. 2013 Mar;39(2):262-8. doi: 10.1016/j.burns.2012.06.009.
3. Simpson MJ, McInerney S, Carr EJ, Cuttle L. Quantifying the efficacy of first aid treatments for burn injuries using mathematical modelling and in vivo porcine experiments. Sci Rep. 2017 Sep 7;7(1):10925. doi: 10.1038/s41598-017-11390-y.

4. Pfurtscheller K, Petnehazy T, Goessler W, Wiederstein-Grasser I, Bubalo V, Trop M. Innovative scald burn model and long-term dressing protector for studies in rats. J Trauma Acute Care Surg. 2013 Mar;74(3):932-5. doi: 10.1097/TA.0b013e31827d0fc3.

5. Iliukhin EA, Bulatov VL, Galchenko MI. [Reliability and accuracy of measuring the surface area of phantom skin lesions with lesionmeter mobile application]. Flebologiia. 2020;14(4):266-274. Russian. doi: 10.17116/flebo202014041266.

6. Masson-Meyers DS, Andrade TAM, Caetano GF, et al. Experimental models and methods for cutaneous wound healing assessment. Int J Exp Path. 2020;101:21-37. doi: 10.1111/iep.12346.

7. Zou W, Yang Y, Gu Y, Zhu P, Zhang M, Cheng Z, Liu X, Yu Y, Peng X. Repeated blood collection from tail vein of non-anesthetized rats with a vacuum blood collection system. J Vis Exp. 2017 Dec 10;(130):55852. doi: $10.3791 / 55852$.

8. Ali Z, Bhaskar SB. Basic statistical tools in research and data analysis. Indian J Anaesth. 2016 Sep;60(9):662-669. doi: 10.4103/0019-5049.190623.

9. Griffin BR, Frear CC, Babl F, Oakley E, Kimble RM. Cool running water first aid decreases skin grafting requirements in pediatric burns: a cohort study of two thousand four hundred ninety-five children. Ann Emerg Med. 2020 Jan;75(1):75-85. doi: 10.1016/j.annemergmed.2019.06.028.

10. Nagaichuk VI, Khimich SD, Zheliba MD, et al. [Modern technologies of treatment of patients with critical and supercritical burns]. [Rep Vinnytsia Natl Med Univ]. 2017;21(2):428-433. Ukrainian.

11. Wright EH, Tyler M, Vojnovic B, Pleat J, Harris A, Furniss D. Human model of burn injury that quantifies the benefit of cooling as a first aid measure. Br J Surg. 2019 Oct;106(11):1472-1479. doi: 10.1002/bjs.11263.

12. Bennett CV, Maguire S, Nuttall D, Lindberg DM, Moulton S, Bajaj L, Kemp AM, Mullen S. First aid for children's burns in the US and UK: an urgent call to establish and promote international standards. Burns. 2019 Mar;45(2):440-449. doi: 10.1016/j.burns.2018.09.003.

13. Sutton D, Wright MD. Cooling for thermal burns: clinical effectiveness and guidelines [Internet]. Ottawa (ON): Canadian Agency for Drugs and Technologies in Health; 2019 [cited 2020 Dec 12]. Available from: https://europepmc.org/article/nbk/nbk541209.

14. Tobalem M, Harder Y, Tschanz E, Speidel V, Pittet-Cuénod B, Wettstein R. First-aid with warm water delays burn progression and increases skin survival. J Plast Reconstr Aesthet Surg. 2013 Feb;66(2):260-6. doi 10.1016/j.bjps.2012.09.014.

15. Fadeyibi IO, Ibrahim NA, Mustafa IA, Ugburo AO, Adejumo AO, Buari A. Practice of first aid in burn-related injuries in a developing country. Burns. 2015 Sep;41(6):1322-32. doi: 10.1016/j.burns.2015.02.018.

\section{Author's ORCID iD and academic degrees}

Roman Chornopyshchuk, MD, PhD, Assistant Professor of Surgery - https://orcid.org/0000-0001-5422-7495

\section{Author's contributions}

$\mathrm{RC}$ conceptualized the idea, conducted literature review, wrote the manuscript, revised and finalized the text.

\section{Funding}

The study was supported by National Pirogov Memorial Medical University, Vinnytsya, Ukraine. The trial was the author's initiative. The author is independent and takes responsibility for the integrity of the data and accuracy of the data analysis.

\section{Ethics approval and consent to participate}

The research project was approved by the Research Ethics Committee of National Pirogov Memorial Medical University, Vinnytsya, Ukraine (protocol No 2, 18.03.2021).

\section{Conflict of Interests}

No competing interests were disclosed. 